\title{
14
}

\section{Technology as a Tool for Environmental Engagement. The Case of Digital Participatory Mapping (DPM)}

\section{Nohemi Ramirez Aranda and Rubén Vezzoni}

\section{Introduction}

Digital innovation opens up new possibilities of exploring scientific methods beyond what is traditionally accepted in research. This process can be smooth and linear, but often it creates tensions, misunderstandings, and unmet expectations. The means to access and create data are rapidly changing, and so is the knowledge creation process,

N. Ramirez Aranda (凶)

Flanders Research Institute for Agriculture, Fisheries, and Food (ILVO),

Merelbeke, Belgium

e-mail: nohemi.aranda@ilvo.vlaanderen.be

Department of Geography, Ghent University, Ghent, Belgium

R. Vezzoni

LUKE (Natural Resources Institute Finland), Helsinki, Finland

University of Helsinki, Helsinki, Finland 
pushing the boundaries of academic work into new grounds. Crowdsourcing online platforms and Geographical Information Systems (GIS) are good examples of this. In this chapter, we reflect on some original ideas concerning the genesis and direct consequences of adopting digital tools in research, with a particular focus on new forms of participation in defining geographies of space, and planning activities from the bottom-up.

Section 14.1 touches on the progression of participatory mapping, its origins, and its incursion in the digital era. Moreover, it argues how its digital and creative nature can be an asset in making participatory processes more democratic and inclusive. Section 14.2 describes two real applications of this technology used in case studies in Belgium and the Netherlands. Section 14.3 presents the challenges and opportunities faced in the case studies, giving special attention to forced creativity, data quality matters (such as precision and accuracy), and digital participatory mapping's complementarity with traditional research methods. Lastly, Sect. 14.4 provides a comprehensive conclusion and discussion of the critical points emerging in the chapter.

\section{Participatory Mapping Origins}

Amid the 1930's modernist movements for rethinking cities and housing in the United States, the foundations of participatory mapping were laid through community surveys and hearings (Guldi, 2017). An early example shows rudimentary but effective participatory maps as court documents by the Cree people to protect their land from developers (Poole, 1995). Ever since, participatory mapping has been slowly evolving and migrating to more digital means through software such as GIS (Chambers, 2006). GIS (programs for collecting, storing, and integrating spatial data analysis) have since found extensive research applications. Several criticisms have, however, emerged in the last decades, calling for a more socially aware type of GIS. Dunn (2007) suggests that this would mean paying greater attention to local spatial knowledge than the technological aspect. The context of the application and the people involved in the process would then be the core elements of 
this new type of GIS that give legitimacy to research's social aspects. This new type of GIS comes when the silent majority is in dire need of tools that bridge their necessities and local knowledge with practitioners and policymakers. If used effectively, these bridging tools can feed government actions, so their benefits can be equitably distributed while reflecting people's needs more accurately. Consequently, these alternative approaches have eventually established a well-defined scientific niche as participatory mapping (PM).

\section{Putting Participation in GIS}

In the mid-1990s, two major academic events paved the way for combining GIS technologies with social issues. The first was the 1993 "GIS and Society" workshop by Poiker (National Center for Geographic Information and Analysis-NCGIA). Second, the 1996 workshop organized by Onsmd, Schroeder, and Lopez at the University of Maine. Both events focused on improving GIS access, especially for those who have been historically under-represented (Obermeyer, 1998). These early attempts to harness the potential of GIS for democratic participation were first labelled under the term Public Participation GIS (PPGIS). PPGIS gradually metamorphosed into a multidisciplinary concept involving different stakeholders and goals (Sieber, 2006). This has led to several variations of the term, such as Participatory GIS (PGIS) or Volunteered Geographic Information (VGI), to be interchangeably used with PPGIS. These terms often share the same essence and their mild differences are not always clear-cut (McCall, 2004).

Brown and Kyttä (2014) propose a characterization of the different types of participatory mapping based on their essential characteristics, as shown in Table 14.1. Although some distinctions can indeed resonate with the history of the tools or their context of application (e.g., PPGIS and PGIS started to be developed in different parts of the globe, respectively in industrialized countries vs. peripheral countries), we argue that current power dynamics and technological advancements have blurred some of these distinctive traits. A strict definition of them is, therefore, of little value for this chapter. Alternatively, we adopt the definition that the 
Table 14.1 Characteristics of PPGIS, PGIS, and VGI (extracted from Brown and Kyttä (2014))

\begin{tabular}{|c|c|c|c|}
\hline & PPGIS & PGIS & VGI \\
\hline Process emphasis & $\begin{array}{l}\text { Enhance public } \\
\text { involvement to } \\
\text { inform land use } \\
\text { planning and } \\
\text { management }\end{array}$ & $\begin{array}{l}\text { Community } \\
\text { empowerment } \\
\text { Foster social } \\
\text { identity } \\
\text { Build social } \\
\text { capital }\end{array}$ & $\begin{array}{l}\text { Expand spatial } \\
\text { information } \\
\text { using citizens } \\
\text { as sensors }\end{array}$ \\
\hline Sponsors & $\begin{array}{l}\text { Government } \\
\text { planning } \\
\text { agencies }\end{array}$ & NGOs & $\begin{array}{l}\text { NGOs, ad hoc } \\
\text { groups, } \\
\text { individuals }\end{array}$ \\
\hline Global context & $\begin{array}{r}\text { Developed } \\
\text { countries }\end{array}$ & $\begin{array}{l}\text { Developing } \\
\text { countries }\end{array}$ & Variable \\
\hline Place context & $\begin{array}{l}\text { Urban and } \\
\text { regional }\end{array}$ & Rural & Variable \\
\hline $\begin{array}{l}\text { Importance of } \\
\text { mapped data } \\
\text { quality }\end{array}$ & Primary & Secondary & Primary \\
\hline $\begin{array}{l}\text { Sampling } \\
\text { approach }\end{array}$ & Active: probability & Active: purposive & $\begin{array}{l}\text { Passive: } \\
\text { voluntary }\end{array}$ \\
\hline Data collection & $\begin{array}{l}\text { Individual (e.g., } \\
\text { household } \\
\text { sampling) }\end{array}$ & $\begin{array}{l}\text { Collective (e.g., } \\
\text { community } \\
\text { workshops) }\end{array}$ & Individual \\
\hline Data ownership & $\begin{array}{l}\text { Sponsors of the } \\
\text { process }\end{array}$ & $\begin{array}{l}\text { People and } \\
\text { communities } \\
\text { that created } \\
\text { data }\end{array}$ & $\begin{array}{l}\text { Shared (e.g., } \\
\text { data } \\
\text { commons } \\
\text { license) }\end{array}$ \\
\hline $\begin{array}{l}\text { Dominant } \\
\text { mapping } \\
\text { technology }\end{array}$ & Digital & Non-digital & Digital \\
\hline
\end{tabular}

same authors proposed in a more recent paper (Brown \& Kyttä, 2018), suggesting identifying all the nuanced alternative concepts mentioned above under the umbrella term of participatory mapping (PM). More specifically, we will hereafter use the term digital participatory mapping (DPM) to identify PM's non-physical practices.

Since its first conceptualizations in the 1990s, the adoption of DPM has been gradual due to technological and cost limitations. The early 2000 s tech revolution brought cheaper, faster, and more resourceful computers, a variety of software, data availability, integration of remote sensing technology, and the launch of new satellites (GIS Geography, 
2020). This combination of events has turned DPM into a cost-effective technique potentially reachable from everywhere and by anyone.

The groundwork laid by decades of technological advancement has indeed increased DPM's capabilities and accessibility to the masses, making its use in diverging contexts by academics possible (Mccall \& Dunn, 2012). Nonetheless, DPM is still not widely adopted by governmental organizations. The rationale behind this is that its results contain potentially sensitive issues that can create dilemmas for policymakers (Carton, 2005; Sulistyawan et al., 2018). Therefore, it is perhaps no surprise that the main ambassadors and advocates of DPM are academics who have tested, modified, and re-tested DPM tools in real-life scenarios where power dynamics are skewed against the underprivileged masses in society.

One of the highest ambitions of researchers using DPM, especially those with a sociological background, is to help break down power hierarchies (Guldi, 2017). Using DPM, less privileged groups in society can be empowered through access to tools previously only accessible to government officials, practitioners, professionals, and policymakers (Sieber, 2006). It is a context-specific application of GIS technology meant to harness indigenous knowledge through community engagement and social learning. Concerning its relationship with traditional research methods in spatial studies, according to Dunn (2007, p. 616), it "celebrates the multiplicity of geographical realities rather than the disembodied, objective and technical 'solutions' which have tended to characterize many conventional GIS applications”.

In many participatory mapping studies, especially in those contexts of low levels of digital literacy, communities' knowledge is gathered through physical, low-tech data collection methods, e.g., drawing ephemeral maps in the sand (Poole, 1995), building physical models (Rambaldi, 2010), or stickers on paper maps (Brown \& Pullar, 2012). To their advantage, these methods are straightforward and do not require the respondents to have any technical mapping or IT skills. Accordingly, from the pool of academic literature regarding PM, there is a predominance of articles referring to physical data collection methods. This imbalance emphasizes the shortage of articles focused on collecting data 
solely using creative and online DPM methods, despite their surge in the past ten years.

Whereas some literature already exists concerning the advantages and drawbacks of these forms of traditional (i.e., physical) PM, DPM and its contextual application remain a rather new subject (Brown \& Reed, 2009). Digital technology may support innovative ways of empowering marginalized social groups, giving voice to unheard local communities, or strengthening the methodological baggage of emerging transdisciplinary sciences (see also Axinte, this book). In this chapter, therefore, we intend to explore the possibilities offered by DPM as visual methods. Moreover, we try to bring to light its capabilities for remote participation, integration of additional input by participants, and the spare the burden of double-entry of information. For the reasons outlined above, we deliberately do not cover other kinds of research methods involving physical activities.

\section{Description of Digital PM Tools}

Thanks to technological advancements (e.g., widely available Internet access, user-friendly GIS interfaces, and mainstream use of mobile devices), DPM has become a cost-effective approach for spatial data collection and a promising method for map co-creation (see also Axinte, this book). However, it is not a panacea for all participation and democratization problems. In Sect. 14.3, we further discuss the challenges and opportunities of DPM.

The tech revolution of the early twenty-first century and a rising interest in the academic environment have paved the way for PM to establish itself as a scientific discipline. These technological advancements provided different platforms upon which the foundations of DPM were built. In the last two decades, scientific literature shows a transition from spatial data collected through low-tech physical methods to digital online alternatives. In the online category, three main types of GIS tools can be distinguished: software, native apps, and web apps.

Software packages are on the heavier end, although there are alternative options, including extensions on standard GIS software to adapt it 
for the specific type of participation (Allen \& Christensen, 2001; Dieber, 2003). Notwithstanding these are quite flexible tools, they rely heavily on participants' technical skills and capable hardware access. The incursion of community map-based services (e.g., open street maps), open-source GIS software (e.g., QGIS), and the mainstream of mobile devices have helped DPM tools to become cheaper, lighter, and friendlier. This has also enabled a shift from bulkier packages to lighter web versions on mobile devices. Native apps are built based on the specific device's OS on which they will be installed, e.g., Android, IOS, and can be built on the research's specific needs, offering limitless possibilities of customization. On the downside, they might require a skilled developer to build and update them properly, which can be pricey.

On the other hand, web-based apps can be customized but do not need to be installed, require fewer resources since they run through the Internet browser, and are cheaper as their architecture and update require less effort. DPM web apps' success has led companies such as ESRI and Maptionnaire to capitalize on it by offering GIS survey services to governments and the general public. They offer DPM tool "templates" that can be customized based on customers' needs as well as access and handling of the collected data in a simple manner.

\section{DPM and Transdisciplinary Research: Towards more Democratic Participation Practices}

In the 1960s, Jane Jacobs was the Cassandra of spatial planning, fighting rationalist planners driven by a capitalist boom and stubborn politicians who deliberately disregarded science and people. Back then, opportunities and channels for citizens to be included in planning processes and decision-making were just not there yet. Moreover, planning trends were mostly intra-disciplinary, leading to segregated solutions for problems that required an holistic approach. This was reflected in the countless "urban renewal programs" (Jacobs, 1994) that affected entire neighbourhoods and destroyed the social fabric in and around them.

However, technological advances in the last two decades have enabled people to increase their role in decision-making and co-creation of cities 
together with planners and practitioners. The GIS technology used in DPM offers valuable capabilities that can be put at the service of transdisciplinary research to tackle the major challenges we face as a species. Think about climate change, natural hazards, cultural heritage, security, health, or poverty. All these challenges require spatial information on a variety of scales if they are to be addressed. Moreover, they all require a comprehensive understanding of the place and interaction of (countless) things and people, in space and time, that a few decades ago would have been impossible to acquire.

More than ever, connecting with strangers across gender, race, class, and space is fairly easy. This is especially true when $60 \%$ of the world population uses the Internet and possesses a mobile device (Statista, 2020). DPM tools, such as the examples given in the following case studies section, can provide insightful information reflecting the many different perspectives each of its contributors had across populations' width and length over a vast range of disciplines, formats, and languages. When this content is put into planners' and policymakers' hands, DMP becomes a channel that boosts representative democracy. It creates or reinforces legitimacy in governance by providing a ground for stakeholders to interact in the twin processes of executing various mapping actions and then analysing the visualized results.

Moreover, DPM creates opportunities to visualize the interests, needs, and potentials of disparate groups in participatory spatial mapping. In this way, those governing are provided with a mechanism to recognize and appreciate the legitimacy of the governed's local interests. DPMs can also foster community participation, allowing capacitybuilding, management, and planning initiatives by the communities. These include skills development and increased confidence in dealing with external economic and political powers, professionals, and technical experts, and heightened attitudes of community "ownership" of the data and maps produced, giving them a better opportunity to control the data and entitlement to any projects making use of the mapping.

In the following sections, we describe two case studies of DPM web apps: "My Green Place" and the "Greenmapper". 


\section{Case Studies}

\section{Case Study 1: My Green Place Ghent}

My Green Place/Ghent was the pilot test of a DPM tool that is the centrepiece of the doctoral research, with the working title of "Public Participation GIS as a tool for improving community management and preservation of green open spaces in Belgium" by Nohemi Ramirez Aranda. The joint research between the Institute for Agricultural, Fisheries, and Food Research (ILVO) and the geography department of Ghent University focuses on improving the management and preservation of green open spaces by including communities' social values in the planning process. Moreover, the ongoing project aims for a tool that allows a more inclusive participation process, giving special attention to those groups that current processes do not reach, such as teenagers, migrants, and older adults.

It was necessary to create a web tool to map communities' social values attached to green open spaces. We wanted to make it as remote, fast, and cheap as possible while keeping the possibility of people of different backgrounds using it. Budget and time/space limitations finally drove us to a digital option. Moreover, a digital tool could (in theory) help combat the "self-selection bias" issue by reaching those citizens that represent the majority but are rarely present in the participation process (Bhattacherjee, 2012, p. 81; Fung, 2006; Renn et al., 1993). Let us take an example of a consultation process where people are invited four days in a row for planning workshops. Expectedly, not everyone would be able to miss four days of work to attend the consultation. Self-selection bias then happens when participants choose whether or not to participate in the consultation, and the ones who do are not representative of the population targeted by the study. Nevertheless, if we take away the fact that people would not have to skip work and could "participate" from their homes and at a time convenient for them through DPM, we could mitigate this specific case of bias.

We operationalized social values using the concept of the cultural practice from the cultural ecosystem services framework in Church et al. (2014) as indicators. To get an accurate reading of what these cultural 
practices were and where they happened, it was very important to provide a suitable geographic entity for participants to indicate them digitally in a map. A geographic entity is the drawing tool participants use to provide input. In physical PM, participants tend to provide their input drawing points and polygons in printed maps using pens, markers, or stickers of different colours and sizes depending on the mapped attribute. Despite their limitations, points, and in a lesser proportion, polygons dominate publications (Brown \& Fagerholm, 2015). The selection of a suitable geographic entity to map specific attributes such as cultural practices was a critical concern in the research since depending on how participants interacted with it, the output could vary greatly. Unfortunately, within literature only a few academics had approached the geographic entity dilemma, doing so in a way that was considered insufficient for our study (Brown \& Pullar, 2012). Therefore, the pilot tool tested which geographic entity (point, polygon, and marker) delivered better performance when mapping specific cultural practices.

To maximize our tool's exposure with our target groups, we designed a promotional campaign called "We Love Gent". This consisted of a whole branding image with a very identifiable logo, slogan, and flyers distributed across social media, WhatsApp, and stakeholders' communication channels such as Ghent University, neighbourhood centres, and religious facilities (see Fig. 14.1).

The data collection strategy included testing sites such as schools, care homes, and migration training centres through mobile devices such as computers, smartphones, and tablets. Additionally, we invited people in public areas to participate in the exercise by using their phones. Due to the variety of devices on which we needed the tool to operate and the exercise's one-time nature, installing something on their devices seemed very unlikely. Reasons varied from privacy issues, to the hassle of installing something that will take storage space on their devices and consume data in the background.

In addition to the tool's development cost and the need for it to be cross-platform, these issues played a critical role in choosing a web app over a native app. Moreover, a web app offered additional advantages against a native app. These included: easy maintenance due to a common code base across multiple mobile platforms, compatibility with any older 


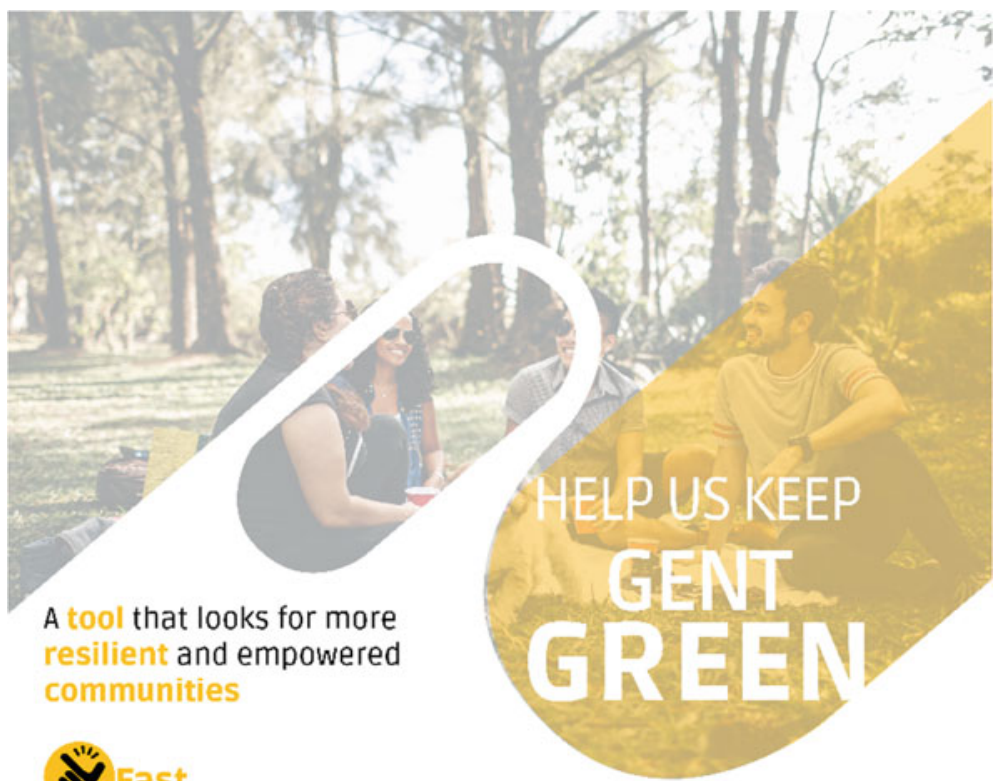

Takes less than 5 minutes.

\section{About}

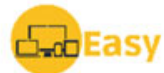

You can access from your smartphone, tablet and computer.

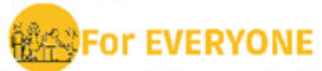

Intuitive and it comes in 8 different languages

\section{We Love Gent}

We Love Gent is a web tool designed by Gent University and ILvo that looks for better management and preservation of green open spaces.

It allows people to indicate their favorite green places, their condition and the things that can be improved. To participate go to www.welovegent. be or scan the QR code below.

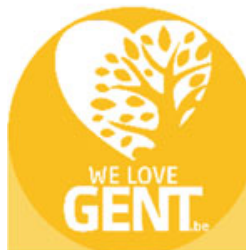

Cus we only protect what we love...

This project has received funding from the European Union's Horizon 2020 research and innovation RECOMS programme under the Morie Sklodowska-Curie grant agreement No 765389
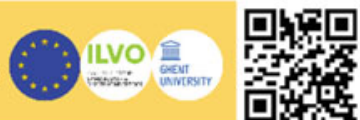

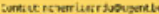

Fig. 14.1 Flyer used for diffusion in the We Love Gent campaign (Source Author) 
mobile device (a particular advantage considering older adults might have outdated mobile devices), and release at the developer's discretion since no app store approval is required.

In the particular case of My Green Place, its development was based on java language with PHP (no framework) using Leaflet JS for the maps, Open Street Map (OSM) as a background layer, and Postgres/PostGIS as database. It runs on a virtual server in Apache, hosted by Ghent University. The layout was made using bootstrap CSS, and all data collected are stored in a secure server from where it can be examined via PgAdmin or QGIS (Fig. 14.2).

The suggestions displayed at the end of the survey were used to maximize the sharing of the tool's link and therefore participant numbers. By providing this map with suggestions of places, participants could share it on their social media and compare their friends' results and suggested places (Figs. 14.3, 14.4, 14.5).

Since the tool could be used on any mobile device with an Internet connection through their Internet browser, the diffusion was relatively simple and cheaper than mail or workshop-based approaches. The link was shared through the Ghent University network, social media, religious, and neighbourhood centres. Moreover, the way the tool itself and collected data are stored provides easy access to fix or adapt the tool in case of need and at a very low to no cost compared to those of a native

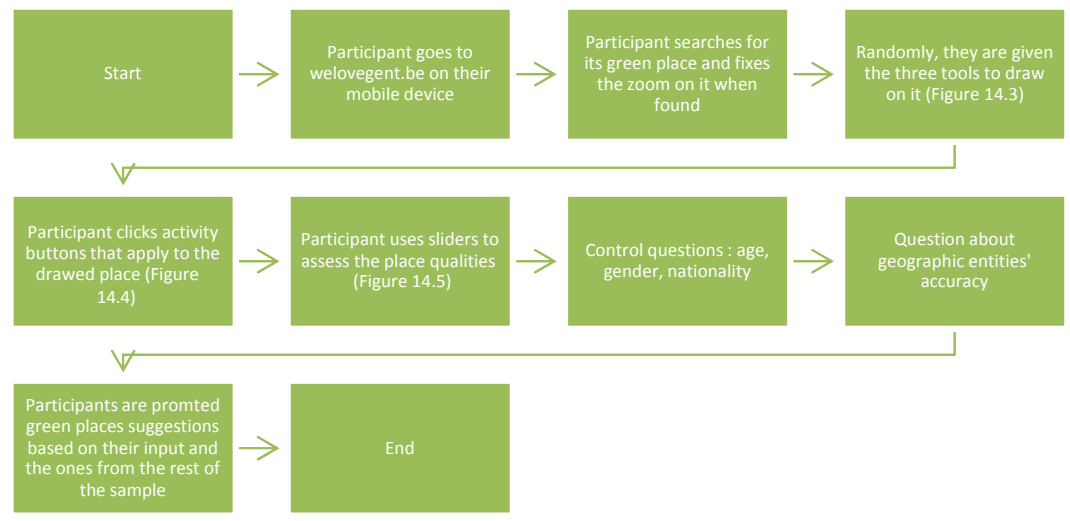

Fig. 14.2 My Green Place demo chart (Source Author) 

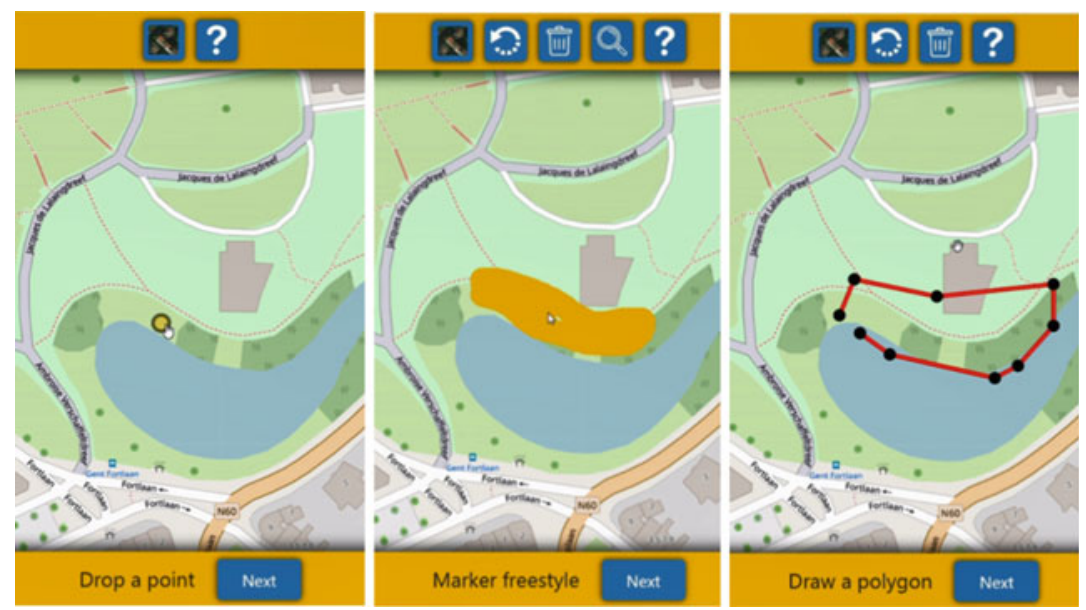

Fig. 14.3 Use of different geographic entities to map cultural ecosystem services in the PPGIS online tool My Green Place / Ghent (Source Author)

app. The main goal of the tool was to test which geographic entity better mapped specific cultural practices. By doing so, we could be sure participants' input provided an accurate representation of their preferences. After five months of data collection and the input of 449 participants, the data collected allowed us to analyse the three geographic entities' accuracy through quadrat analyses, regressions against a constructed collective truth, ${ }^{1}$ and a survey on the three geographic entities' perceived accuracy among respondents. The results showed points performing the weakest, and markers performing the strongest. This was noted, especially when mapping for dynamic cultural practices, implying a displacement across space such as running, biking, and walking. The performance of the polygon was similar to that of the marker, although slightly weaker. The marker not only provided a more precise image of respondents' input, it was also simpler to use and had less risk of spatial errors than offered by the polygon. Therefore, it was concluded that the marker was a suitable

\footnotetext{
${ }^{1}$ To test the suitability of each geographic entity to map cultural practices, we compared the three datasets, namely the aggregation of points, polygons, and markers, to a 'true' representation of respondents' favourite green open spaces per type of cultural practice. Therefore, an estimate of that 'true' representation, denoted as the "Collective Truth" (CT) was built by aggregating the average of points, polygons, and markers per quadrat cell.
} 


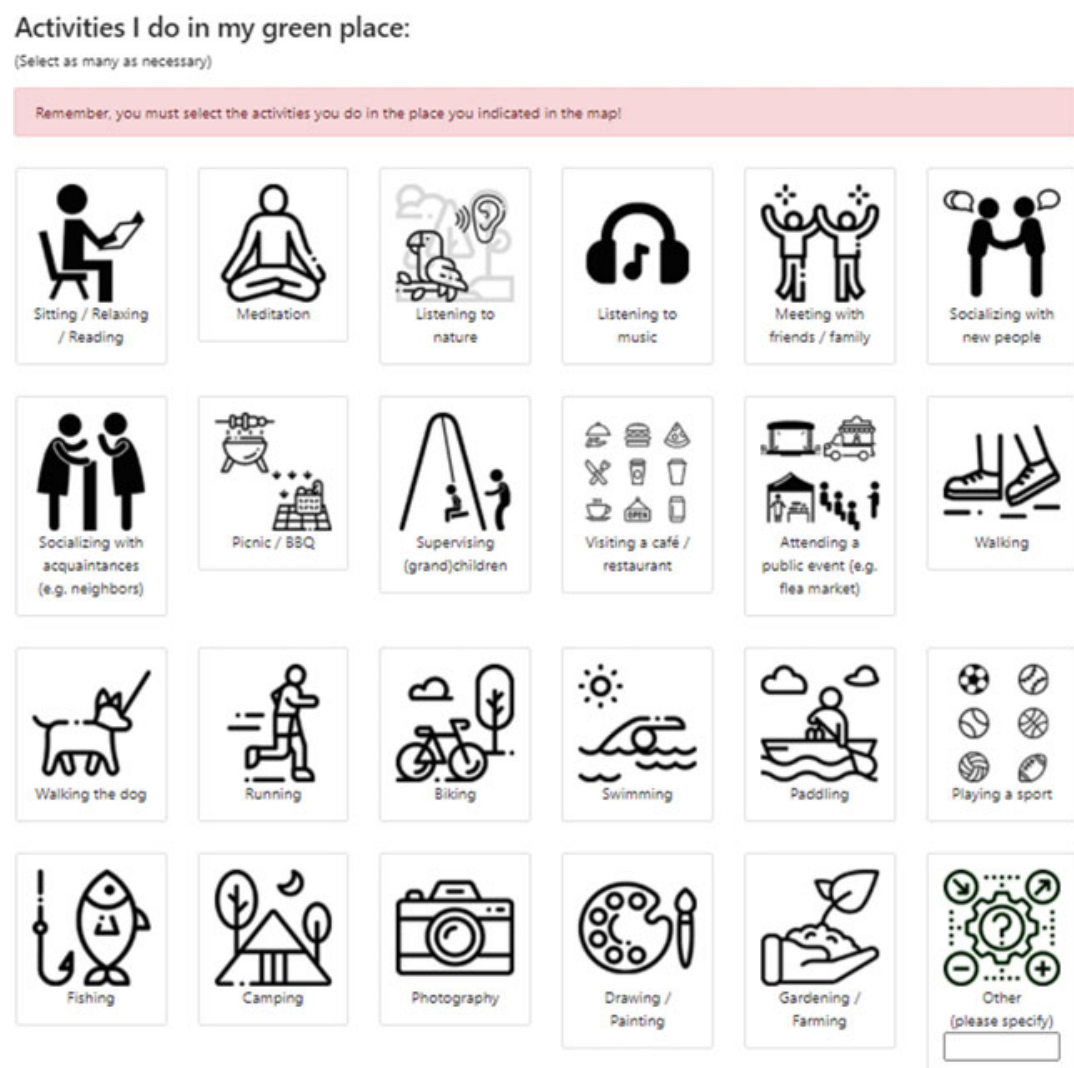

Fig. 14.4 Button section with activities for participants to indicate (Source Author)

alternative to the point and the polygon when collecting spatial data in future cultural ecosystem services research (Aranda et al., 2021).

Another goal of the tool was to test how easy it was to reach teenagers, migrants, and older adults. In this regard, the data showed that the biggest group to use the tool was teenagers, followed by young adults. Regarding migrants, the criteria used to test this was "nationality"; this was proven ineffective for our purposes since, e.g., participants who were second-generation Turkish or had just recently settled in the country will still identify themselves as "Belgians". Several tests were made to get the 


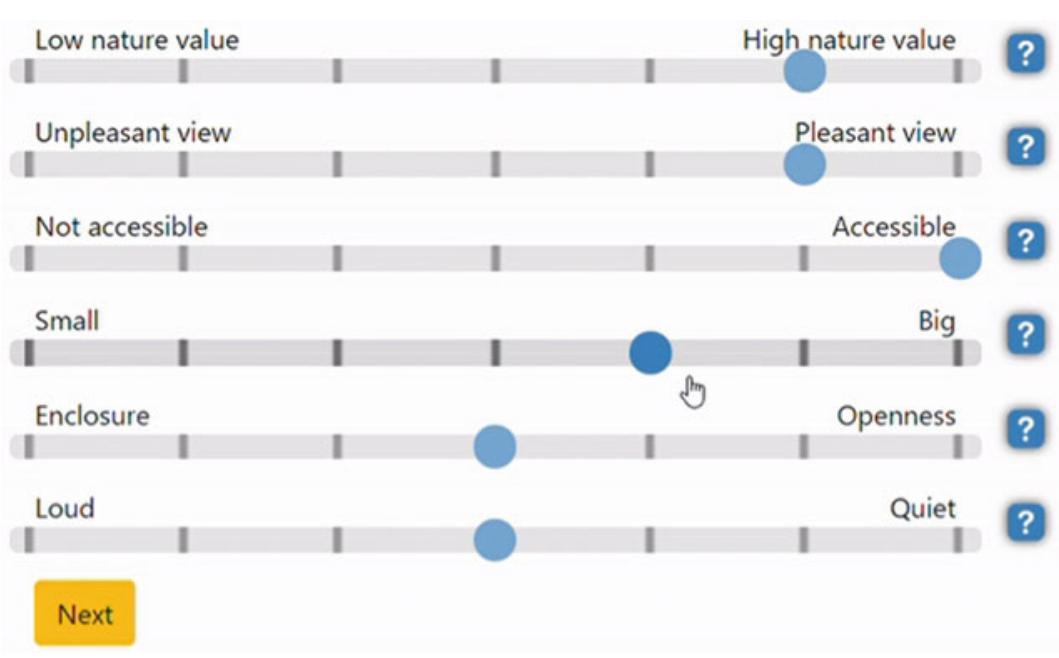

Fig. 14.5 Slider section on My Green Place tool to assess the place qualities (Source Author)

right question to provide what was needed without being too provocative or incurring major GDPR requirements. After the pilot test and the later trials on this specific point, we added two complementary questions about parents' nationality to track migrant backgrounds in the participant's sample. Tracing the migration background proved to be more challenging than expected since asking this is a very sensitive topic in the face of the many ex-pats that have arrived in Europe during the refugee crisis. Even when participants were second or third-generation descendants of migrants, the question posed something uncomfortable that not many were willing to answer.

The 60+ year age group was barely present in the sample, which led to changes for the tool's final version (My Green Place/Woluwe). Since the tool management was done via Pgamin, changes based on the pilot test's feedback were included relatively easily in the tool's next version. Thanks to this versatility, a twin version of My Green Place was used in a research project from the University Hospital of Ghent (UZ Ghent) about how older adults use green open spaces. This twin version was made via a copy of the main My Green Place that kept the tool's essence, such as the layout, buttons, and questions, while adapting it for older 
adults. These adaptations were made based on the feedback we secured from the pilot test and UZ Ghent's cognitive interview results.

Cognitive interviews are useful for getting more information about participants' real experiences using a "product" that cannot be observed directly (Beatty \& Willis, 2007). They provide valuable insights about challenges and opportunities for improvement that participants detect while using certain products or answering certain questions in a survey. The cognitive interviews with older adult participants using the pilot tool My Green Place showed that the tool was too difficult. Zooming in to a particular place and operating both polygon and marker drawing tools to indicate the places they visited required considerable effort. Additionally, older adults seemed to constantly forget that they were meant to indicate which activities and attributes were found in the place they had selected on the map. Instead, they tended to select activities and attributes they wished or liked to do but not particularly in the place they selected. To handle these issues, the twin version of My Green Place highlights in green all areas within Ghent in the category of "green open spaces", e.g., parks, cemeteries or farmlands (see Fig. 14.6). Then, before continuing

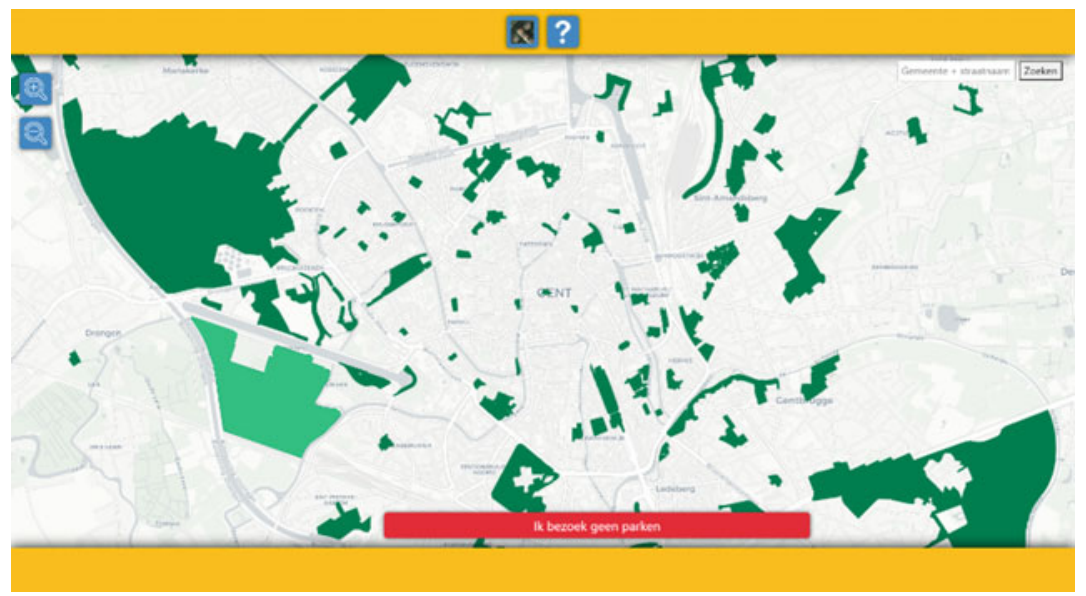

Fig. 14.6 Twin version of the My Green Place tool, offering a preselected view of Ghent's green places for the older adult group (Source Author) 
with the interview, the system asks for confirmation from participants concerning the selected area.

To address the issue of them providing general preferences (instead of attributes specific to the place they had marked), selected additional popup messages were strategically inserted to constantly remind respondents that their input should be based on what they did or found in the place they had selected (see Figs. 14.6, 14.7 and 14.8). These small but focalized adaptations to the original tool proved to be effective in the second round of cognitive interviews.

In tests where bigger groups were reached at once, such as classrooms or mass events, we carried out a series of feedback sessions. In

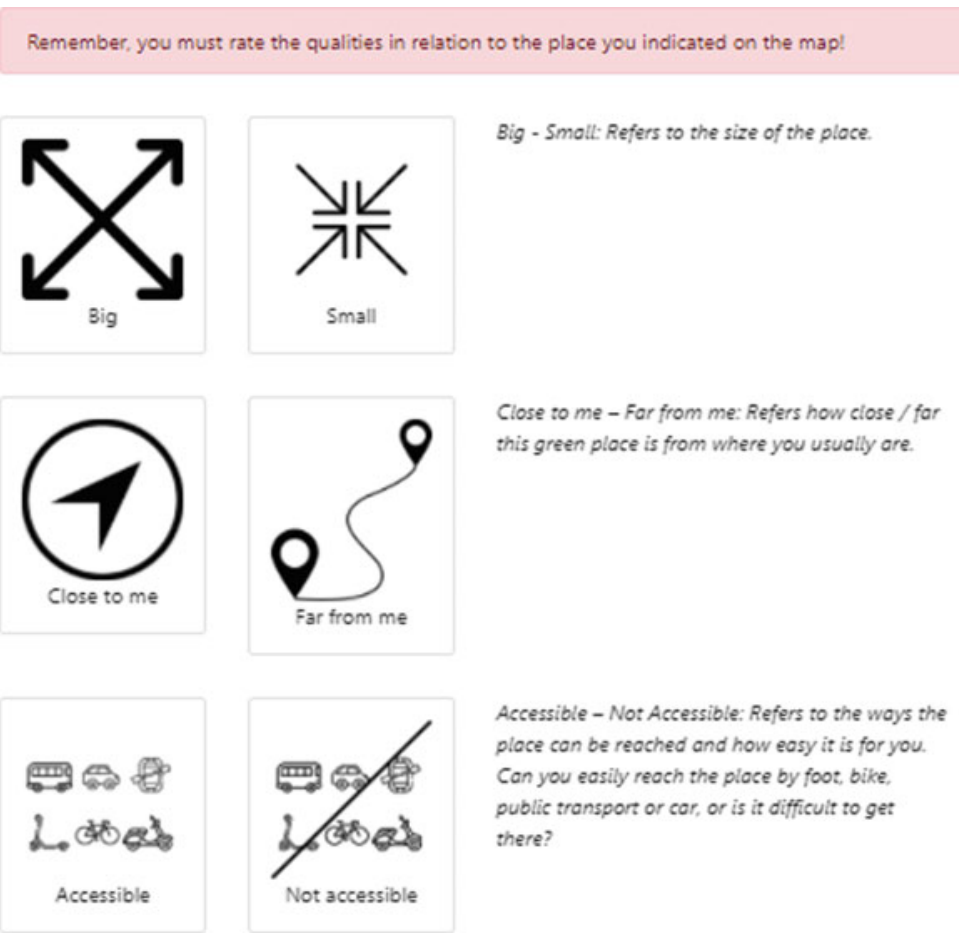

Fig. 14.7 Adaptation in the My Green Place tool to aid the older adult group to remember what attributes and activities to select (Source Author) 


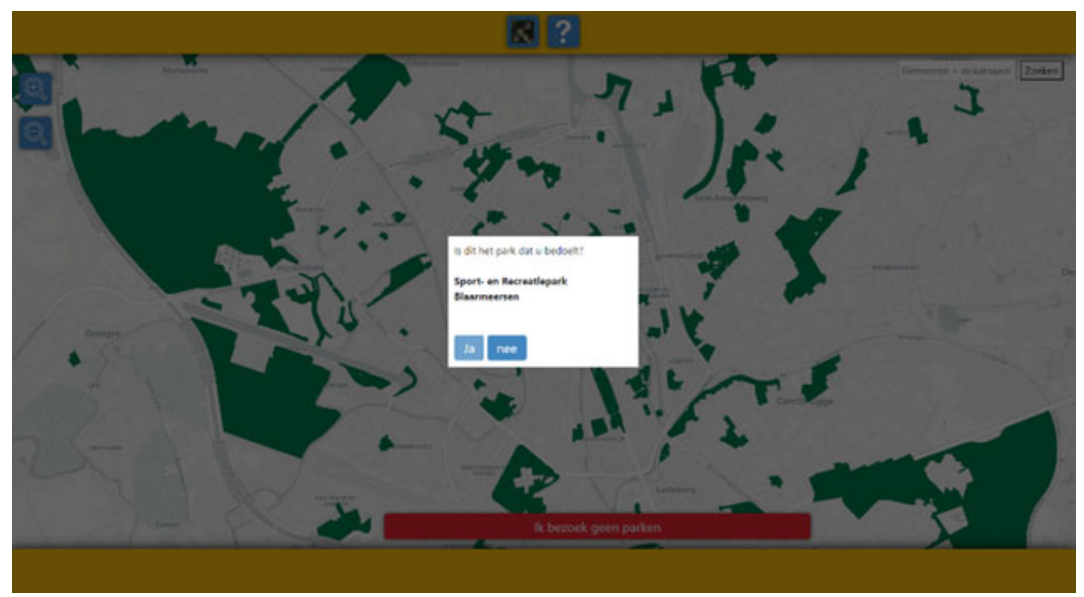

Fig. 14.8 Adaptation in the My Green Place tool to aid the older adult group to remember which places to select (Source Author)

these sessions, participants could, using "post-its", provide direct feedback about issues such as how easy or difficult it was to use the tool, if they found it relevant, or if it was the first time they were consulted in such a way. In addition, we could get valuable information about things we missed regarding activities, elements people found important, and survey questions that could help us better understand the bond and attachments people have with particular green places.

Through these sessions, we made citizens content creators by using the tool and developers, since it was through their feedback and interest that the next iteration of the tool was shaped. By actively participating in shaping the tool, they also become more committed to sharing it and using the outputs as grounds for shifting the direction of any plans that do not fit the collective interest. 


\section{Case Study 2: Multi-Level Governance and Partaking in Research on the Greenmapper}

According to environmental psychology, the unique bonds that human beings develop with natural places have a key regulatory role in selfidentity, such as self-esteem maintenance (Korpela, 2002). This is what Williams and Vaske (2003) call place identity, namely "the symbolic importance of a place as a repository for emotions and relationships" (ibid., p. 831). Place identity occurs both at the individual and the aggregate level (i.e., community level) and across various geographical scales, well beyond the area of residence (Cuba \& Hummon, 1993; Hidalgo \& Hernández, 2001). Thanks to easier international traveling and increasing globalized imaginaries, Bijker and Sijtsma (2017) have demonstrated that citizens-at least in Western countries-have a clear "portfolio of natural places" spanning from the local scale to favourite places at the planetary level. Consequently, citizens from different parts of the world may be attached to the same natural place, constituting what Sijtsma et al. (2019) refer to as the "community of fans".

Therefore, the "community of fans" is a heterogeneous social conglomerate in which different particular interests coexist. Simplifying for the sake of clarity, a primary distinction exists between those people living in or next to the natural place and the rest of the fans. The demands of these two groups can diverge, sometimes to the extent of being antithetical (e.g., usage vs. conservation). Therefore, multi-level governance is needed to functionally coordinate social bodies for delivering mutually beneficial outcomes (Brondizio et al., 2009). In the presence of different and stratified interests, ${ }^{2}$ multi-level governance through DPM platforms is used to reveal the otherwise invisible needs, motivations, and participation preferences of the actors involved. This is what Cox (2014) has referred to as the orchestrations of "management activities carried out by different sets of actors at different spatial scales" (ibid., p. 312).

\footnotetext{
2 The diversity of particular interests represents the dissimilarities among citizens living in different places (e.g., in preferences or requests) as well as those between public authorities and other actors involved in the management of the natural resource.
} 
In addition to being characterized by a variety of particular demands, the members of a "community of fans" may also have different possibilities and preferences for contributing to the natural area's maintenance. For example, citizens living far away from their favourite places may have difficulty in providing physical support (e.g., collecting garbage); nonetheless, they may be willing to provide remote help (e.g., funding). The potential of financial support for natural places from online communities (e.g., crowdfunding) has already been investigated in literature (Bijker et al., 2014), although usually limited to specific areas or ecological services. The relevance of the subjective value attributed to the place and the geographical scale has often been overlooked. The Greenmapper.org provides a DPM platform for exploring the different ways in which citizens want to participate in support of their favourite natural areas, considering both the uniqueness of their individual contributions and the importance of the geographical scale.

The Greenmapper software (www.greenmapper.org) is a crowdsourcing platform developed at the University of Groningen, the Netherlands. It is a web-based participatory GIS platform based on Google Maps, previously known as HotSpotMonitor (HSM) (Sijtsma et al., 2012). Users can register with their home location and then mark their favourite natural places at four geographical levels: local, regional, national, and global. The data collected shed light on the participants' value to the natural places they find more attractive. After marking a natural place, respondents are asked to specify the type of connection they have with the place and why it is important for them (Fig. 14.9). This process is repeated at the local, regional, national, and global levels. Bijker and Sijtsma (2017) also used these four geographical scales in their study on the "portfolio of natural places", as shown in Fig. 14.10. The nature of these scales is obviously arbitrary. They come from the researchers' need to systematize the study, and they are interpreted based on individual perceptions of the participants' space. Nonetheless, it is useful to frame all the studies according to the same structure as it eases data collection and comparative analysis.

Following the previously introduced definition of a digital "community of fans" (Sijtsma et al., 2019), the Greenmapper is designed to 


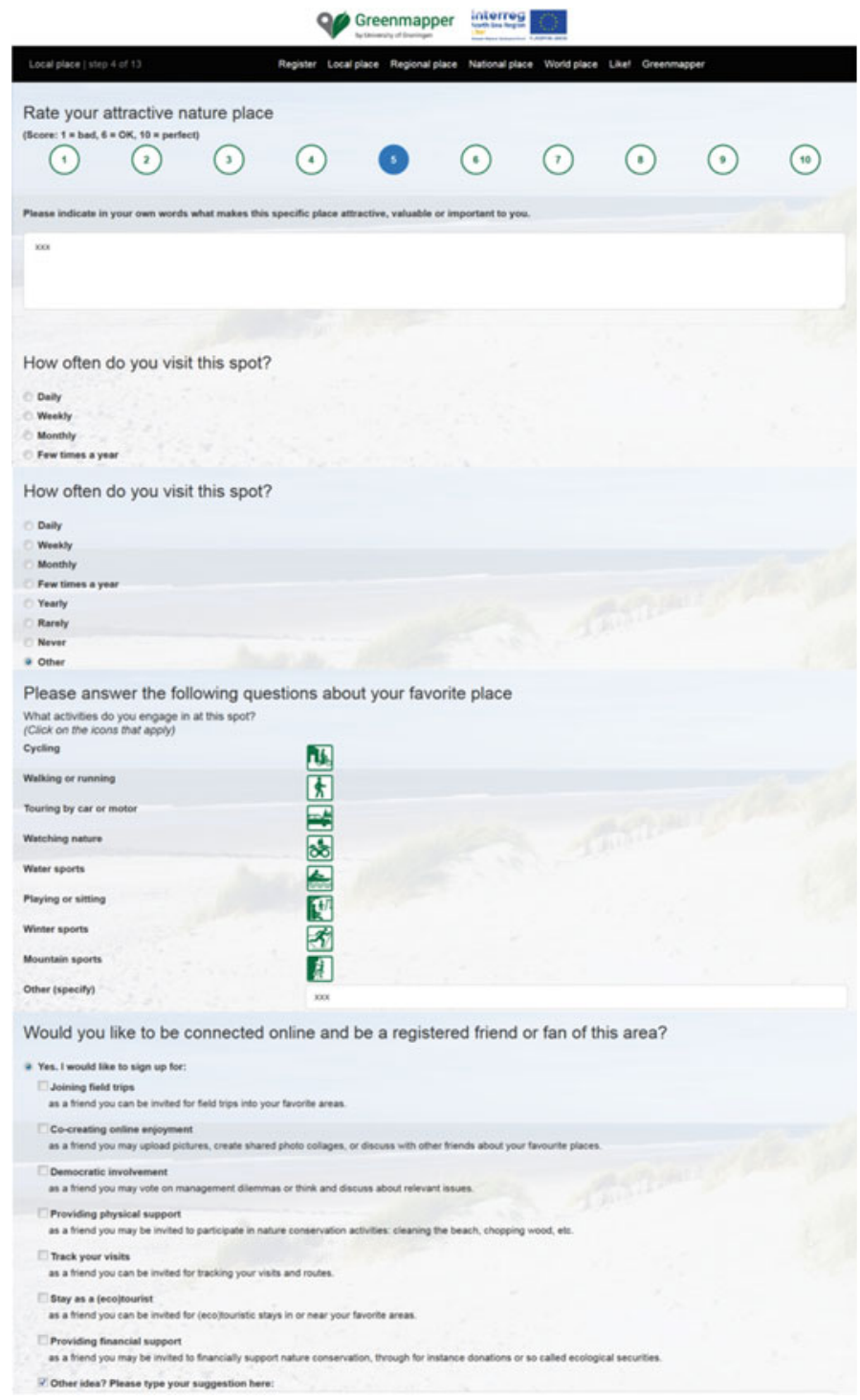

Fig. 14.9 Basic steps for registering for the Greenmapper survey. The figure shows the questions for the local place. The iterative process is repeated for every geographical level, i.e., local, regional, national, and global (Source Author) 


\section{Local place}

Rated on average 7,7
$\mathbf{2 k m}$ from home
Most often visited weekly or monthly
Important quality: Green, nature
Physical activities, relaxing and nature
watching
Counterbalance to the hustle of urban life
Place for physical activities, picnicking

\section{National place}

Rated on average 8,4

$276 \mathbf{~ k m}$ from home

Most often visited few times a year or yearly

A higher natural and landscape quality and recreational options

Walking/swimming, relaxing, nature

watching, café/terrace

Deeper, more intense feelings

\section{Regional place}

Rated on average 8,1

$13 \mathrm{~km}$ from home

Most often visited monthly/few times a year

A larger variety of natural qualities

Walking, relaxing, nature watching and

café/terrace

Counterbalance to the hustle of urban life

Place for physical activities, picnicking

\section{World place}

Rated on average 8,6

$3361 \mathrm{~km}$ from home

Most often visited yearly or rarely

A higher natural and landscape quality and recreational options

Walking/swimming, relaxing, nature

watching, café/terrace

Deeper, more intense feelings

Fig. 14.10 Summary of the average "portfolio of natural places" for urban residents. (Source Bijker and Sijtsma 2017)

explore the reasons behind this connection and how to enable interaction between community members. Crowdsourcing through DPM is, in this case, used to identify these communities and enable their existence (Brown \& Kyttä, 2018). Collecting thousands of respondents from several countries (e.g., the Netherlands, Germany, Denmark, Italy, Switzerland, Brazil, South Korea), the Greenmapper is creating a worldwide database connecting citizens, and their favourite natural places, with one another.

In the latest development of the Greenmapper software, Vezzoni and Sijtsma (2020) explore DPM's possibilities to design online financial mechanisms for nature conservation. DPM tools are a suitable method for transdisciplinary research. In this case, for instance, they have been used to combine research methods from different disciplines, such as contingent valuation from environmental economics, with the study of multi-level governance from the institutional analysis. Additionally, the 


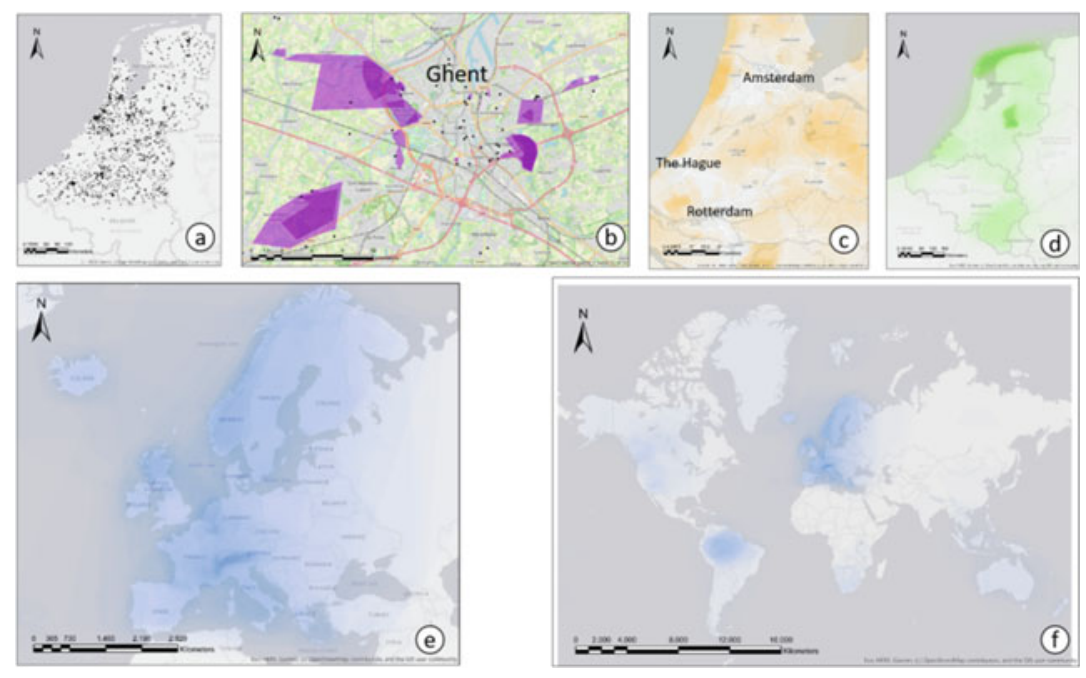

Fig. 14.11 Spatial results of the Greenmapper survey (Source Vezzoni and Sijtsma CCBY): (a) location of respondents, (b) local polygons in Ghent, (c) regional polygons in the Netherlands, (d) national polygons in the Netherlands, (e) and (f) global polygons

research's participatory element allows the respondents to define firsthand the locations in which the experiment ${ }^{3}$ takes place. This has both the advantage of improving the accuracy of the results and enabling the collection and analysis of novel types of data pools.

Vezzoni and Sijtsma (2020) also introduce a new feature of the Greenmapper, namely the possibility of drawing polygons around favourite natural areas instead of marking them with a point. In line with $\mathrm{My}$ Green Place and other studies using participatory mapping (see Table 14.1), polygons deliver additional information concerning overlapping areas of common interest. For example, while points only allow for the clustering of interesting regions, with polygons the authors can create heat maps in which the intensity of the colour indicates the overlying of respondents' interests (Fig. 14.11).

\footnotetext{
3 The experiment here refers to the contingent valuation section of the study. In this case, contingent valuation methods were used to infer on the willingness to pay expressed in euros per $\mathrm{km}^{2}$.
} 
The introduction of polygons in the Greenmapper software has been made in combination with the design and testing of a new type of digital funding mechanism: landscape ownership. Dividing the map into spatial shares (composed, in this case, of $1 \mathrm{~km}^{2}$ each), the participants in the research can select and virtually buy (i.e., fund) the landscapes in their favourite areas. Landscape owners can exert a role of governance over the natural places, even though the property rights belong to a third party. A simplified example of landscape ownership's functioning may help to clarify its connection with multi-level governance principles. A landowner, such as a National Park, agrees with a DPM platform (e.g., the Greenmapper) on a $€ / \mathrm{km}^{2}$ price for each share. The platform users can then buy shares of their favourite natural areas and form a personal portfolio of landscape shares managed by the DPM platform. The funding collected is directed to the National Park with a binding description of how and where to spend the budget. In return, whenever a major change will affect the area's landscape, the National Park agrees to communicate it to the landscape owners and let them partake in the decisional processes. In line with the principle of multi-level governance, landscape ownership allows different actors' voices to be heard and enables the coordination of multiple and stratified interests, making the average citizen an active player rather than a passive spectator (Arnstein, 1969).

The innovative potential of digital technology in research lies in the malleability of online tools such as DPM to adapt and complement traditional research methods. In the case studies presented in this chapter, digital tools have been used to stratify the richness of results by dramatically enlarging the sampled population and the diversity and complexity of each participant's responses. DPM methods allow Greenmapper users to partake in the design of research experiments instead of relying on given research settings. 


\section{Building on the Case Studies: Challenges and Opportunities of DPMs}

"Cities have the capability of providing something for everybody, only because, and only when, they are created by everybody".

Jane Jacobs

This section will address some of the challenges and opportunities that the DPM tools offer. These have been selected based on the authors' experiences in their case studies and the limited links between them that literature offers. We will therefore discuss issues related to the dangers of pushing DPM as a solution to ease and defer conflicts emerging in society and communities. Moreover, we will address data quality issues that arise when collecting and analysing digital data from a diverse audience. Finally, we will explore DPM's role in planning consultations compared to "traditional" (physical) participatory methods.

\section{Forced Creativity in DPM}

In Chapter 2, "The Managerial University" (see Leitheiser et al., this book), we warned against the danger of forced creativity. Forced creativity refers to the co-optation of creative research methods by the dynamics characterizing the institutional setting in which they are mobilized. In the context of a highly managerial university, identified by increasing competition for funding and precarious job positions, DPM and other creative and visual methods may even end up exacerbating the problems they try to address. To start this section on the challenges of DPM, we expand on the idea of forced creativity by illustrating the case of artwashing.

Artwashing is the strategy of managing discontent by giving an "artsy" touch to solutions that impact the appearance but not the problem's substance (Novak, 2019). It has an anaesthetic effect on the transformative potential of using creativity in research. Artwashing practices relate more to marketing strategies than scientific methods, potentially 
converting community involvement into a promotional campaign ${ }^{4}$. The narrative of participation in governance advanced by researchers using DPM is exposed to the danger of engaging with communities without actually having any possibility of empowering them (see also Reitz, this book, and Axinte, this book). DPM is an effective tool for eliciting the individual values and preferences of the participants. However, while social and cultural recognition is an important aspect of democratic practices, redistribution of power is often at risk of being neglected (Fraser, 1997). Even if the development of means, such as DPM, that can facilitate the share of information to, from, and with citizens, is consistent with democratic principles, it does not automatically enable the emergence of emancipatory actions. On the contrary, it could be a counterproductive exercise, creating the illusion of democratic involvement on paper and deception in practice.

According to Friedmann (1992), participation is more effective if it occurs early enough in the planning process. This kind of strategy can serve as a safety net to prevent the process from being co-opted by a particular political agenda. A practical example will help to clarify the concept. Once citizens become involved, the logical next step would be to expect that change will come to their local green place. This was a very sensitive topic among those citizens using My Green Place. More often than not, participants would directly address the researcher, asking when their park would be renovated or intervened. Although the researcher has actively worked to put local issues in the spotlight using a variety of resources, expectation management has to be addressed at the very start of any participation session. The researcher is responsible for always being clear with citizens participating in the study about the intentions of the research so that false expectations are avoided.

In the case of landscape ownership presented in the Greenmapper case study, the boundary between empowering mechanisms and deceiving practices is a blurry one. Without a clear (contractual) agreement between the landowner, the platform, and the share buyer, chances exist that the DPM's result remains limited to yet another way of collecting

\footnotetext{
${ }^{4}$ For example, the citizens of Boyle Heights (Los Angeles, US) created a grassroot organization precisely to prevent the cultural gentrification that goes under the label of artwashing. http:// alianzacontraartwashing.org/en/bhaaad/.
} 
funding from citizens. It adds innovation to the method's appearance for the simple fact that it uses digital means, but it does not transgress the traditional structure of the study. The researcher would still be able to objectify the results, the participant would remain the passive object of the study, and the outcome would simply be a one-way financial contribution to nature conservation.

\section{Data Quality: Precision and Accuracy}

Accuracy and precision are two key factors that have to be addressed to ensure the quality of collected spatial data and avoid possible bias. They rely on a series of factors from which choosing a suitable geographic entity is a critical one. A geographic entity's suitability to map certain attributes can compromise the collected data and any results coming from it if neglected. A clear example of this can happen when mapping dynamic activities such as running. Imagine people are asked to map places where they run using two different geographic entities: a point and a polygon. Although mapping the same item, results will be different since points are incapable of mapping beyond one place, whereas the polygon allows tracing better routes and complete surfaces. If participants were only given the point option, that would inevitably lead to biased data, faulty analysis, and mistaken conclusions.

Precision refers to how participants place a geographical entity (e.g., point, polygon) in a map, either printed or digital. Precision when mapping can be determined by factors such as the size of the object used for mapping (e.g., marker or a pen's width, stickers size), the map's scale, participants' visual capacity and dexterity (Brown \& Pullar, 2012). The last two factors can weigh heavily in people who suffer an impairment or are advanced in age, causing a potential bias in this group (Gottwald et al., 2016). Precision is more significant when using physical data collection methods than digital ones. The number of open variables in the process, e.g., quality of the printed map, marker width or sticker size, and later processing to digital format, leaves much room for spatial error. Brown and Pullar (2012) discussed this issue and how particular types of 
marker colours, printed maps, and stickers can produce defective input, which has to be discarded since it is not up to quality for analysis.

When using DPM, current map services like Google Maps or open street maps that provide flexible map scales may (in theory) increase precision by allowing participants to adjust better the area where they will point out an attribute on their screens (Brown \& Pullar, 2012). It is nonetheless important that the researcher guides the participants in the process of interacting with the maps. In the case of the Greenmapper, for example, data have often been collected through large online surveys. Considering the different geographical scales of the software (i.e., local, regional, national, global), it has been noticed that participants tend to select larger areas the bigger the scale is. Favourite places at the global level are several times larger than those selected at the local level. The possibility of improving precision through, for example, the zooming option is not well understood unless explicit guidelines are provided. This highlights a selection bias due to the scale that can easily distort results if it is not properly treated.

Accuracy can be determined by factors such as how well instructions are provided, the nature of what is being mapped, and participants' map literacy. Mapping specific attributes, especially those perceived as abstract, e.g., "pleasant view" or "relaxation" using a single point, can lead to an inaccurate representation of input as a direct consequence of using an unsuitable geographical feature for its capture. This brings to light the importance of choosing a suitable geographic feature for the particular attribute to be mapped to avoid this kind of bias. Recalling the case studies presented above, the My Green Place pilot in Ghent addresses this particular situation by comparing every participant's input for the same attribute using three different geographical features (point, polygon, marker). Similarly, the Greenmapper has recently introduced the possibility of drawing polygons instead of points.

When data collection for the "We Love Gent" pilot test was done, large groups of people gathering together in one place for any occasion was something feasible, safe, and granted. However, after the COVID-19 pandemic hit the world and restrictive measures were put in place from March 2020 onwards, gatherings of any type were unfeasible, at least physically. This meant that one of the advantages of doing PM physically 
(the capability of bringing people together, working, and discussing one topic) was temporarily lost. In this way, the fact that DPM allows remote data collection without gathering people in one place at a specific time is an asset to the current scenario. Furthermore, the quarantine's mental and physical effect on people worldwide has led many to increase their need for and appreciation of green open spaces. This has made many realize the value that DPM tools such as My Green Place can bring to people trying to find a pleasant piece of nature nearby them while engaging in the process of management and conservation.

\section{Digital Tools: Complementary to rather than Substitutes for Traditional Methods}

Intuitively, digital platforms give researchers new possibilities, including, but not limited to, increasing the number of respondents reached by a survey, the size of datasets, and improving the dissemination of results. However, a few aspects should be considered that may have counterproductive consequences. First, as we have shown above with the examples of precision and accuracy, increased quantity does not imply increased quality. On the contrary, it may have distortive effects on data reliability (Al-Salom \& Miller, 2017). The researcher provides the first filter in the collection of data during, for instance, fieldwork activities. Substituting it with digital tools for large-scale surveys may lead to distortive effects. In fact, respondents may have fewer incentives to provide meaningful answers and may be exposed to a higher range of distractions (Hardré et al., 2012). In the case of research studies directly rewarding respondents (e.g., students participating in research studies as part of university courses), DeRight and Jorgensen (2015) show that poor quality data accounts, on average, for $10 \%$ of all digital surveys directly rewarding respondents. Similarly, participation in scientific data collection can be reduced to a mere utilitarian calculus, as it is common practice for Internet panel services to pay participants to respond. The risk of neglecting the quality of in-person data collection compared to web-based methods has to be considered. 
Second, researchers using DPM as a creative method should also be aware that they are not an unequivocally time-effective tool. As mentioned above, the time spent on cross-examining and filtering large datasets of dubious quality can balance out the time saved on in-person interviews or other fieldwork activities. However, the perhaps greater limitation of digital technology is in the imperfect substitutability of data from digital tools and real-life exchanges. Particularly in the case of research methods for which communities' involvement is a core element, like DPM, we stress that the researcher's physical presence can determine the reliability and soundness of the study. In these cases, the study's technological or productivity-oriented character should not prevail on its anthropological attributes.

Third, digital tools have high start-up and running costs. For instance, an individual researcher is unlikely to have the skills and time needed to design, create, and maintain online platforms. These processes often involve research groups and outsourcing of services to consultancy companies or academic spin-offs. It is not a simple task to predict the value of the research results a priori, as well as being in contradiction with a rigorous scientific approach. However, assuming that the results and the digital tool itself will be shared with the scientific community (and beyond) may also make the effort of investing in a new digital tool worthwhile. The high costs and time effort required argue for sharing access to the digital tool to the broadest audience possible. This is in line with recent calls for open-science to use digital technology to democratize access to science instead of creating an elitist tool, i.e., accessible only for those in a financially privileged position.

Fourth, the funding structure of DPM is often challenging. Founders of projects using DPM frequently forget the importance of disseminating and maintaining the digital tool. Suppose the intentions are creating a successful tool. In that case, a DPM platform needs not only financial support for the development phase (which represents the most substantial part of the funding structure anyway) but also budget specifically allocated for reaching the target audience and for keeping the tool working overtime. The "We Love Gent" campaign effort to reach our target audience was made via the delivery of printed media such as flyers in concurred places across the city and invitations by email through the 
university network. Additionally, a couple of secondary schools shared the link and allowed us to talk to students about the project and the importance of people being engaged in managing their green places. Posting weekly invitations on Facebook groups, as well as sharing the link to the tool via WhatsApp groups from certain neighbourhoods and religious centres, also proved to be a good strategy to engage with more participants at relatively low cost.

However, in the second stage of the tool, the new campaign called "We Love Woluwe" has had to invest more in remote advertising due to the impossibility of reaching groups of people, e.g., in parks, stations, schools, or care homes due to the concurrent COVID-19 restrictions. The strategy includes paid advertising of the tool's link in social media such as Facebook and Instagram in the eight municipalities where the research is being conducted. Moreover, to address the older adult group, we mailed postcard invitations. Although the cost itself of sending a postal card via local Belgian post is relatively cheap (€0.09 per $25 \mathrm{gr})$, the rental service for accessing the database of residents and filtering our target groups can vary from $€ 500$ to $€ 5,000$ or more, depending on the complexity of the filter and the group size.

Many older adults rarely have access to a computer or the knowledge to use it. Nevertheless, now more than ever, aging populations are turning to technology in mobile phones and tablets (AARP Research, 2020). Therefore, by reaching them with a postcard invitation to participate, they can do so via their mobile devices. Social media platforms offer a wide array of options and budgets to promote any product. Furthermore, depending on the research needs, it can hardly be a fraction of the price and time required to hire field researchers to do the collection manually.

\section{Conclusions}

The almost century-long tradition of participatory mapping is entering a new era. In the last decades, information technology has radically changed the field, mostly through the adoption of GIS techniques. Drawing on the review presented by Brown and Kyttä (2018), in this 
chapter we focused our analysis on digital practices of participatory mapping, or DPM. Digital technology is enabling citizens to increase their stake in the decision-making process. Although its adoption is not a cure-all, at the very least it gives scholars and practitioners an unprecedented opportunity to expand participation in the co-creation of spaces and planning policies. The solution to most of the challenges we face in the twenty-first century, from climate change to control of pandemics, requires spatial information on different scales. This is not to mention the democratic gap brought about by rampant increases of inequality and economic opportunities, both at the intra- and inter-national levels. DPM can be used to extend the scope of public policy. The concerns of the many can now partake in the decision-making process beyond the vested interests of the few.

However, as already mentioned, it is critical to acknowledge that DPM tools are not a panacea. For example, they can be an easy target for tokenism, as in artwashing practices. Practitioners and researchers may be incentivized to trumpet new participation methods, such as DPM, instead of making the participation process effective and influential. As Fraser (1997) suggests, we stress the relevance of considering redistribution of power together and beyond social recognition. The researcher is often not in a position of changing the composition of institutionalized power in the short term, and is surely not alone. This is not in itself a weakness of DPM. Nonetheless, it should be openly acknowledged not to generate false expectations. For DPM to be truly effective, it is important to avoid the paradox of "empowering without power".

Assuming technological progress to be neutral per se, both advances and downsides may accompany the adoption of digital tools. For instance, we have shown that data quality collected through DPM is not unequivocally better in terms of precision and accuracy than in person collection. While precision refers to the technical aspects that influence the mapping activity, accuracy identifies the subjective factors that influence the data's interpretation from both the participant and the researcher. Brown and Pullar (2012) show the relevance of assessing participants' visual capacity and dexterity, which we have explored in this chapter's two case studies. At the same time, the researcher or practitioner should also be aware of their own positionality. The way they give 
instructions, the subjective nature of what is being mapped, or the expectations that arise from participating in this process are likely to influence the study's accuracy.

Concerning the composition of DPM datasets, digital technologies represent a major improvement in information accessibility. However, while it may be a powerful tool to improve representativeness and engage with socially marginalized groups, a certain bias still exists concerning access to online and digital platforms. This is the case, for example, of older adults. The My Green Place case study shows how early recognition of the target audience and planning can help to mitigate this selection bias.

Digital tools are indeed a major improvement in mapping, but the examples above mark the importance of not throwing the baby out with the bath water. Instead of being perfect substitutes, DPM should be considered as a complementary tool to in-person activities. Fieldwork can mitigate the distortive effects of large-scale online surveys, such as recognizing problems of selection bias or inaccurate framing of the questions, e.g., not fitting the context-specific characteristics of the place (Al-Salom \& Miller, 2017). For example, in the data collection phase, the researcher often provides a first filter that can significantly improve the study's soundness. In any case, participatory mapping is transdisciplinary as it rests at the intersection of different fields, from geography to humanities. The technologically driven performance of these new digital tools should not neglect their anthropological characteristics.

\section{DPM and What Lies Ahead}

Technological developments keep making GIS cheaper and more accessible. The potential of DPM tools will keep growing, and with it the possibilities to make participatory planning practices more democratic. DPM provides a bridge between citizens and public stakeholders that fosters transparency, accountability, and legitimacy (McCall, 2003). Therefore, there is little doubt that these tools will help to improve citizen participation in planning processes. 
While writing this chapter, the COVID-19 pandemic has dramatically changed how we interact with others, at least for the time being. Standard participation practices, where face-to-face interactions were the norm, became suddenly unfeasible. This presented a challenge but also a great opportunity to test DPM capabilities. For example, data collection with My Green Place (in the "We Love Woluwe" campaign ${ }^{5}$ ) also continued during the pandemic thanks to its digital character. The same goes for the Greenmapper that has always been operating globally, collecting data from remote locations, even before most research was forced to move online.

DPM tools can provide means for legitimizing local demands by collecting quantitative and qualitative data (Poole, 1995) However, this is not enough to achieve multi-level governance and truly democratic participation (McCall, 2003). A paradigm shift is needed for solving the mistrust that many decision-makers still have in participatory mapping processes, such as DPM. We recognize that DPM tools alone cannot make participatory planning better or more influential for the future. This would require a joint effort from the bottom-up with the support of citizen organizations. At the end of the day, citizens are the main source of information feeding the decision-making process.

Social media and the Internet offer an easily accessible means of sharing information and propel causes across different scales. Notwithstanding a certain institutional stiffness, the world is changing. The radically new ways of living dictated by the digital era, climate change, and increasing demands for democratic representation will eventually sweep away old habits of "doing planning". Some researchers and planners are already aware of this trend, and they are adapting their approaches accordingly, together with the institutions they represent.

Acknowledgements This research received funding from the European Union's Horizon 2020 research and innovation programme under the Marie Sklowdoska-Curie Grant Agreement No. 765389.

5 "We Love Woluwe" is the third iteration of the My Green Place tool. It was the result of the lessons learned in the "We Love Gent" campaign and the beta version. "We Love Woluwe" collected data from July 2020-March 2021 in the eight municipalities surrounding the Woluwe river, located between Brussels and the Flemish region. 


\section{References}

AARP Research. (2020). 2020 Tech trends of the 50+. Available at: https:// www.aarp.org/content/dam/aarp/research/surveys_statistics/technology/ 2019/2020-tech-trends-survey.doi.10.26419-2Fres.00329.001.pdf.

Allen III, W. L., \& Christensen, J. (2001, July). Managing a land trust with geographic information systems. In Presentation at the Annual ESRI Users' Conference (pp. 9-15), San Diego, CA.

Al-Salom, P., \& Miller, C. J. (2017). The problem with online data collection: Predicting invalid responding in undergraduate samples. Modern Psychological Studies, 22(2).

Aranda, N. R., De Waegemaeker, J., Venhorst, V., Leendertse, W., Kerselaers, E., \& Van de Weghe, N. (2021). Point, polygon, or marker? In search of the best geographic entity for mapping cultural ecosystem services using the online public participation geographic information systems tool, "My Green Place." Cartography and Geographic Information Science. https://doi. org/0.1080/15230406.2021.1949392

Arnstein, S. R. (1969). A ladder of citizen participation. Journal of the American Planning Association, 85(1), 24-34. https://doi.org/10.1080/01944363. 2018.1559388

Beatty, P., \& Willis, G. (2007). Research synthesis : The practice of cognitive interviewing. Public Opinion Quarterly, 71(2), 287-311. doi: https://doi. org/10.1093/poq/nfm006.

Bhattacherjee, A. (2012). Social science research: Principles, methods, and practices (2nd ed.). Tampa.

Bijker, R., Mehnen, N., Sijtsma, J. F., \& Daams, M. (2014). Managing urban wellbeing in rural areas: The potential role of online communities to improve the financing and governance of highly valued nature areas. Land, 3(2), 437-459. https://doi.org/10.3390/land3020437

Bijker, R. A., \& Sijtsma, F. J. (2017). A portfolio of natural places: Using a participatory GIS tool to compare the appreciation and use of green spaces inside and outside urban areas by urban residents. Landscape and Urban Planning, 158, 155-165. https://doi.org/10.1016/j.landurbplan. 2016.10.004

Brondizio, E. S., Ostrom, E., \& Young, O. R. (2009). Connectivity and the governance of multilevel social-ecological systems: The role of social capital. 
Annual Review of Environment and Resources, 34(1), 253-278. https://doi. org/10.1146/annurev.environ.020708.100707

Brown, G., \& Fagerholm, N. (2015). Empirical PPGIS/PGIS mapping of ecosystem services: A review and evaluation, . Ecosystem Services, 13, 119133. https://doi.org/10.1016/j.ecoser.2014.10.007

Brown, G., \& Kyttä, M. (2014). Key issues and research priorities for public participation GIS ( PPGIS ): A synthesis based on empirical research . Applied Geography, 46, 122-136. https://doi.org/10.1016/j.apgeog.2013. 11.004

Brown, G., \& Kyttä, M. (2018). Key issues and priorities in participatory mapping: Toward integration or increased specialization? Applied Geography, 95, 1-8. https://doi.org/10.1016/j.apgeog.2018.04.002

Brown, G., \& Reed, P. (2009). Public participation GIS: A new method for national park planning. Landscape and Urban Planning, 55(2), 166-182. https://doi.org/10.1016/j.landurbplan.2011.03.003

Brown, G. G., \& Pullar, D. V. (2012). An evaluation of the use of points versus polygons in public participation geographic information systems using quasi-experimental design and Monte Carlo simulation. International Journal of Geographical Information Science, 26 (2), 231-246. https://doi.org/ $10.1080 / 13658816.2011 .585139$

Carton, L. (2005). How to cope with map controversies in deliberative policy making. Mapping for Change (PGIS), Nairobi, September, (March 2002), pp. 1-24. Available at: http://www.iapad.org/publications/ppgis/linda_car ton.pdf.

Chambers, R. (2006)/ Participatory mapping and geographic information systems: Whose map? Who is empowered and who disempowered? Who gains and who loses? The Electronic Journal of Information Systems in Developing Countries, 1-11. doi: https://doi.org/10.1002/j.1681-4835.2006.tb0 0163.x.

Church, A., Fish, R., \& Haines-Young, R. (2014). UK national ecosystem assessment follow-on. Work package report 5: Cultural ecosystem services and indicators.

Cox, M. (2014). Applying a social-ecological system framework to the study of the Taos valley irrigation system . Human Ecology, 42(2), 311-324. https:// doi.org/10.1007/s10745-014-9651-y

Cuba, L., \& Hummon, D. M. (1993). A place to call home: Identification with dwelling, community, and region. Sociological Quarterly, 34(1), 111-131. https://doi.org/10.1111/j.1533-8525.1993.tb00133.x 
DeRight, J., \& Jorgensen, R. S. (2015). I Just want my research credit: Frequency of suboptimal effort in a non-clinical healthy undergraduate sample. The Clinical Neuropsychologist. Routledge, 29(1), 101-117. https:// doi.org/10.1080/13854046.2014.989267

Dieber, M. (2003). Paint the town: Lessons learned. Presentation at the second annual conference on PPGIS, 20-22 July, Portland.

Dunn, C. E. (2007). Participatory GIS: A people's GIS?. Progress in Human Geography, 616-637. https://doi.org/10.1177/0309132507081493.

Fraser, N. (1997). From redistribution to recognition? Dilemmas of justice in a "post-Socialist" age. In Justice interruptus. Critical reflections on the "Postsocialist" condition (pp. 68-149). Routledge. doi: https://doi.org/10.1002/978 0470756119.ch54.

Friedmann, J. (1992). Empowerment: The politics of alternative development. Blackwell Publishing Ltd. Available at: https://www.wiley.com/en-be/Emp owerment $\% 3 A+T h e+$ Politics+of+Alternative+Development-p-978155786 3003\#download-product-flyer.

Fung, A. (2006). Varieties of participation in complex governance. Public Administration Review, 66(SUPPL. 1), 66-75. https://doi.org/10.1111/j. 1540-6210.2006.00667.x

GIS Geography. (2020). The remarkable history of GIS where did GIS begin ? Stages of GIS development. Available at: https://gisgeography.com/historyof-gis/.

Gottwald, S., Laatikainen, T. E., \& Kyttä, M. (2016). Exploring the usability of PPGIS among older adults: Challenges and opportunities . International Journal of Geographical Information Science, 30(12), 2321-2338. https://doi. org/10.1080/13658816.2016.1170837

Guldi, J. (2017). A history of the participatory map. Public Culture, 29(1), 79-112. https://doi.org/10.1215/08992363-3644409

Hardré, P. L., Crowson, H. M., \& Xie, K. (2012). Examining contexts-of-use for web-based and paper-based questionnaires. Educational and Psychological Measurement, 72(6), 1015-1038. https://doi.org/10.1177/001316441 2451977

Hidalgo, M. C., \& Hernández, B. (2001). Place attachment: Conceptual and empirical questions. Journal of Environmental Psychology, 21(3), 273-281. https://doi.org/10.1006/jevp.2001.0221

Jacobs, J. (1994). The death and life of great American cities. Penguin Books.

Korpela, K. (2002). Children's environment. In Bechtel, R. \& Churchman, A. (eds.), Handbook of environmental psychology. Wiley. doi: https://doi.org/10. 1016/0307-904X(80)90124-9. 
McCall, M. K. (2003). Seeking good governance in participatory-GIS: A review of processes and governance dimensions in applying GIS to participatory spatial planning. Habitat International, 27(4), 549-573. https://doi. org/10.1016/S0197-3975(03)00005-5

McCall, M. K. (2004). Can participatory-GIS strengthen local-level spatial planning ? Suggestions for better practice, Skudai, Johor, Malaysia.

Mccall, M. K., \& Dunn, C. E. (2012). Geo-information tools for participatory spatial planning: Fulfilling the criteria for "good" governance? Geoforum, 43(1), 81-94. https://doi.org/10.1016/j.geoforum.2011.07.007

Novak, D. (2019). The arts of gentrification: Creativity, cultural policy, and public space in Kamagasaki. City and Society, 31(1), 94-118. https://doi. org/10.1111/ciso.12195

Obermeyer, N. J. (1998). Evolution of public participation GIS. Cartography and Geographic Information Systems, 25(2), 65-66. https://doi.org/10.1559/ 152304098782594599

Poole, P. (1995). Land-based communities, geomatics and biodiversity conservation. Cultural Survival Quarterly, 18(4), 1-4. Available at: http://www.iapad.org/publications/ppgis/landbased_communities_ geomatics_and_biodiversity.pdf.

Rambaldi, G. (2010). Participatory three-dimensional modelling: Guiding principles and applications (2010th ed.). ACP-EU Technical Centre for Agricultural and Rural Cooperation (CTA). Available at: https://bit.ly/38N $\mathrm{dkCe}$.

Renn, O., Webler, T., Rakel, H., Dienel, P., \& Johnson, B. (1993). Public participation in decision making: A three-step procedure. Policy Sciences, 26 (3), 189-214. https://doi.org/10.1007/BF00999716

Sieber, R. (2006). Public participation geographic information systems: A literature review and framework. Annals of the Association of American Geographers, 96(3), 491-507. https://doi.org/10.1111/j.1467-8306.2006. 00702.x

Sijtsma, F. J., Daams, M. N., Farjon, H., \& Buijs, A. E. (2012). Deep feelings around a shallow coast. A spatial analysis of tourism jobs and the attractivity of nature in the Dutch Wadden area. Ocean \& Coastal Management, 68, 138-148. https://doi.org/10.1016/j.ocecoaman.2012.05.018

Sijtsma, F. J., Mehnen, N., Angelstam, P., \& Muñoz-Rojas, J. (2019). Multiscale mapping of cultural ecosystem services in a socio-ecological landscape: A case study of the international Wadden Sea Region. Landscape Ecology, 34(7), 1751-1768. https://doi.org/10.1007/s10980-019-00841-8 
Statista. (2020). How many smartphones are in the world ? Number of mobile phone \& smartphone users, Bankmycell. Available at: https://www.bankmy cell.com/blog/how-many-phones-are-in-the-world.

Sulistyawan, B. S., Verweij, P. A., Boot, R. G. A., Purwanti, B., Rumbiak, W., Wattimena, M. C., Rahawarin, P., \& Adzan, G. (2018). Integrating participatory GIS into spatial planning regulation: The case of Merauke District, Papua, Indonesia. International Journal of the Commons, 12(1), 26-59. https://doi.org/10.18352/ijc.759

Vezzoni, R., \& Sijtsma, F. J. (2020). Multilevel governance in the digital age: Exploring online connectedness and willingness to pay for favourite local, regional, national and global nature places. Manuscript submitted for publication.

Williams, D. R., \& Vaske, J. J. (2003). The measurement of place attachment: Validity and generalizability of a psychometric approach. Forest Science, 49(6), 830-840. https://doi.org/10.1093/forestscience/49.6.830

Open Access This chapter is licensed under the terms of the Creative Commons Attribution 4.0 International License (http://creativecommons.org/ licenses/by/4.0/), which permits use, sharing, adaptation, distribution and reproduction in any medium or format, as long as you give appropriate credit to the original author(s) and the source, provide a link to the Creative Commons license and indicate if changes were made.

The images or other third party material in this chapter are included in the chapter's Creative Commons license, unless indicated otherwise in a credit line to the material. If material is not included in the chapter's Creative Commons license and your intended use is not permitted by statutory regulation or exceeds the permitted use, you will need to obtain permission directly from the copyright holder.

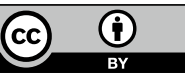

